\title{
PENGARUH SISTEM PENGUKURAN KINERJA KOMPREHENSIF DAN PEMBERDAYAAN PSIKOLOGIS TERHADAP KOMITMEN ORGANISASI
}

\author{
Hidayatul Khusnah, Riyan Sisiawan Putra \\ Fakultas Ekonomi dan Bisnis, Universitas Nahdlatul Ulama Surabaya \\ e-mail: hidayatul.khusnah@unusa.ac.id,riyan_sisiawan@unusa.ac.id
}

\begin{abstract}
A comprehensive performance measurement system is part of the management control function. Overall activities undertaken by employees in strategic planning, budgeting, implementation, and performance evaluation are influenced by the management. This study aims to examine the effect of a comprehensive performance measurement system on psychological empowerment and organizational commitment, as well as the effect of psychological empowerment on organizational commitment at Unusa. Hypothesis testing in this study using Structural Equation Modeling Partial Least Square (SEM-PLS) with WarpPLS 3.0 software. The results of this study indicate that a comprehensive performance measurement system positively affects the psychological empowerment and organizational commitment. The latest findings of psychological empowerment have a positive effect on organizational commitment.
\end{abstract}

Keywords: a comprehensive performance measurement system, psychological empowerment, organizational commitment

\section{A. PENDAHULUAN}

Reformasi birokrasi tidak hanya dilakukan oleh pemerintah saja, namun juga dilakukan oleh organisasi-organisasi lain, salah satunya adalah organisasi sektor publik. Perubahan yang dilakukan oleh organisasi sektor publik mulai dari struktur manajemen publik, akuntansi keuangan dan manajemen, manajemen keuangan, manajemen sumber daya manusia, dan strategi yang berorientasi pada output dan outcome dengan tujuan untuk meningkatkan kinerja dan pelayanan publik (Bogt, 2008).

Reformasi birokrasi tidak hanya dilakukan oleh pemerintah saja, namun juga dilakukan oleh organisasi-organisasi lain, salah satunya adalah organisasi sektor publik. Perubahan yang dilakukan oleh organisasi sektor publik mulai dari struktur manajemen publik, akuntansi keuangan dan manajemen, manajemen keuangan, manajemen sumber daya manusia, dan strategi yang berorientasi pada output dan outcome dengan tujuan untuk meningkatkan kinerja dan pelayanan publik (Bogt, 2008). Di Indonesia, awal mula perubahan sistem administrasi sektor publik terjadi sejak dikeluarkannya Instruksi Presiden (Inpres) Nomor 07 Tahun 1999 tentang Penerapan Sistem Akuntabilitas Kinerja Pemerintah (SAKIP).

Pengukuran kinerja yang dilakukan oleh organisasi pemerintahan biasanya hanya menggunakan pengukuran secara keuangan. Agar pelayanan publik yang semakin baik, maka organisasi pemerintahan hendaknya menggunakan sistem pengukuran kinerja komprehensif yakni pengukuran secara keuangan dan nonkeuangan (Jansen, 2008; Kloot dan Martin, 2000). Sistem pengukuran kinerja komprehensif merupakan bagian dari fungsi pengendalian manajemen. Keseluruhan aktivitas yang dilakukan oleh karyawan dalam perencanaan strategi, penyusunan ang- 
garan, pelaksanaan, dan evaluasi kinerja dipengaruhi oleh pihak manajemen. Dalam melaksanakan aktivitas tersebut harus terdapat pengukurannya untuk mengetahui apakah program dan kegiatan telah sesuai dengan capaian strategi yang ditetapkan atau tidak (Halim dan Kusufi, 2013; Anthony dan Govindarajan, 2007; Nordiawan dan Hertianti, 2010). Sistem pengukuran kinerja komprehensif digunakan untuk melakukan pengendalian internal dan pelaporan kinerja dari keseluruhan aktivitas pemantauan, penilaian, dan manajemen risiko (Pollanen, 2014).

Sistem pengukuran kinerja komprehensif menyajikan informasi mengenai pengukuran secara keuangan dan nonkeuangan dengan perspektif yang berbeda-beda dalam menerjemahkan strategi ke dalam seperangkat ukuran kinerja dan kinerja individu dapat ditingkatkan dengan adanya sumber informasi dan keputusan yang diambil dapat memberikan hasil yang efektif dan efisien (Chenhall, 2005; Kren, 1992). Sistem pengukuran kinerja komprehensif dapat memainkan peran penting dalam mendukung pengembangan manajerial di perusahaan (Garengo et al., 2005). Garengo et al. (2005) mengindikasi bahwa adanya perbedaan yang signifikan antara teori dan praktik tentang pentingnya sistem pengukuran kinerja komprehensif pada perusahaan dalam mendukung pengembangan sistem manajerial.

Penelitian tentang persepsi sistem pengukuran kinerja komprehensif yang berpengaruh terhadap kinerja manajerial dan kinerja organisasi sudah banyak dilakukan (Chenhall, 2005; Spekle dan Verbeeten, 2014; Neely et al., 1995; Nielsen, 2013), namun penelitian mengenai persepsi pengaruh sistem pengukuran kinerja komprehensif terhadap perilaku individu masih jarang dilakukan (Shields et al., 2000; Webb, 2004). Perilaku individu ketika mengimplementasikan strategi ini sangat penting karena adanya perbedaan dalam psikologi sosial dan ekonomi cara individu memberikan tanggapan terhadap sistem pengukuran kinerja komprehensif (Luft, 2004).

Pemberdayaan psikologis merupakan faktor psikologis yang dapat memengaruhi persepsi individu tentang sistem pengukuran kinerja komprehensif untuk peningkatan kinerja manajerial. Persepsi tentang sistem pengukuran kinerja komprehensif yang dimiliki organisasi memberikan kejelasan tujuan karena menyediakan informasi secara menyeluruh yakni informasi pengukuran secara keuangan dan nonkeuangan. Kejelasan tujuan terjadi karena informasi menjadi lebih rinci dan spesifik sehingga peran dan tanggung jawab individu menjadi jelas dan tidak ambiguitas (Hall, 2008; Hassan, 2013). Penelitian bertujuan untuk menguji persepsi individu tentang pengaruh sistem pengukuran kinerja komprehensif terhadap pemberdayaan psikologis dan komitmen organisasi pada Karyawan Universitas Nahdlatul Ulama Surabaya.

\section{B. TINJAUAN LITERATUR DAN PENGEM- BANGAN HIPOTESIS}

1. Sistem pengukuran kinerja komprehensif dengan pemberdayaan psikologis

Sistem pengukuran kinerja menurut Neely et al. (1995) merupakan proses pengukuran kegiatan organisasi yang efektif dan efisien untuk kinerja organisasi menjadi lebih baik. Bowen dan Lawler (1992) menyatakan bahwa informasi dari sistem pengukuran kinerja komprehensif dapat memberikan kejelasan dan peningkatan pemberdayaan psikologis karyawan. Bowen dan Lawler (1992) menambahkan bahwa karyawan yang merasa diberdayakan atau memiliki pemberdayaan psikologis ketika mendapatkan informasi mengenai kinerja organisasi dapat berkontribusi bagi 
kemajuan organisasi dan memiliki kekuatan untuk mengambil keputusan yang berpengaruh di dalam organisasi. Berdasarkan hasil penelitian yang telah dipaparkan di atas, peneliti membuat hipotesis sebagai berikut.

H1: Sistem pengukuran kinerja komprehensif berpengaruh positif terhadap pemberdayaan psikologis

\section{Sistem pengukuran kinerja komprehensif dengan komitmen organisasi}

Tan dan Lau (2010) sistem pengukuran kinerja komprehensif digunakan untuk mengevaluasi kinerja yang dapat memengaruhi tiga outcome yakni keadilan prosedural, kepuasan kerja, dan komitmen organisasi. Hasil penelitian Tan dan Lau (2010) mengindikasi bahwa sistem pengukuran kinerja komprehensif berhubungan positif terhadap komitmen organisasi.

Sistem pengukuran kinerja komprehensif digunakan dalam proses manajemen kinerja yang adil dan untuk meningkatkan kepercayaan antara atasan dengan bawahan sehingga akan meningkatkan komitmen organisasi seorang manajer. Sistem pengukuran kinerja komprehensif berhubungan positif terhadap komitmen organisasi (Sholihin dan Pike, 2010). Berdasarkan hasil penelitian yang telah dipaparkan di atas, peneliti membuat hipotesis sebagai berikut.

H2: Sistem pengukuran kinerja komprehensif berpengaruh positif terhadap komitmen organisasi

\section{Pemberdayaan Psikologis dengan Komitmen Organisasi \\ Castro et al. (2008) menyatakan bahwa} pemimpin yang ingin meningkatkan kepuasan karyawan dan komitmen organisasi karyawan seharusnya dapat mengomunikasikan tujuan organisasi, membina internalisasi tujuan, dan menciptakan pemberdayaan psikologis bagi karyawan. Pemimpin dalam sebuah organisasi harus mampu untuk melaksanakan dengan baik proses transformasional melalui pertimbangan individual, stimulasi intelektual, dan memberikan pengaruh terhadap perilaku individual untuk mencapai strategi dan tujuan organisasi yang diharapkan.

Persepsi karyawan tentang praktik kepemimpinan atau gaya manajemen yang baik akan dapat meningkatkan pemberdayaan psikologis dalam melaksanakan fungsi organisasi sehingga komitmen organisasi juga dapat ditingkatkan (Ismail et al., 2011). Pemberdayaan psikologis berpengaruh positif terhadap komitmen organisasi (Bhatnagar, 2005; Castro et al., 2008). Dari pemaparan hasil penelitian di atas maka peneliti membuat hipotesis sebagai berikut.

H3: Pemberdayaan psikologis berpengaruh positif terhadap komitmen organisasi

\section{METODE PENELITIAN}

\section{Sampel}

Sampel dalam penelitian ini adalah karyawan Universitas Nahdlatul Ulama Surabaya yang sudah bekerja minimal tiga bulan. Pengumpulan data dalam penelitian ini menggunakan survei secara langsung dilakukan dengan cara menyebarkan kuesioner hard copy langsung kepada responden dengan kriteria yang telah ditentukan. Jumlah kuesioner yang disebar 93 dan kuesioner yang kembali 82. Berdasarkan data yang telah dikumpulkan terdapat 11 kuesioner yang tidak di isi dengan lengkap sehingga kuesioner yang dapat digunakan hanya 72 . Persentase tingkat respons dalam penelitian ini sebesar 77\% yang menunjukkan bahwa tingkat respons yang ditunjukkan oleh responden tinggi, yang mengindikasi- 
kan bahwa karyawan Universitas Nahdlatul Ulama Surabaya tertarik untuk berpartisipasi dalam penelitian ini.

\section{Pengukuran Variabel}

\section{a. Sistem Pengukuran Kinerja Komprehensif}

Variabel Sistem pengukuran kinerja komprehensif diukur dengan menggunakan instrumen yang telah digunakan Hall (2008). Variabel sistem pengukuran kinerja komprehensif diukur dengan skala Likert 7 poin yang terdiri dari sembilan item pertanyaan $(1=$ sangat-sangat tidak sesuai sampai $7=$ sangat-sangat sesuai).

\section{b. Pemberdayaan Psikologis}

Variabel Pemberdayaan psikologis diukur dengan instrumen yang diadopsi dari Spreitzer (1995) yang terdiri dari 12 item pertanyaan, yakni tiga item untuk setiap konstruk pemberdayaan psikologis: makna (meaning), kompetensi (competence), determinasi diri (self-determination), dan dampak (impact). Variabel pemberdayaan psikologis diukur dengan menggunakan skala likert $(1=$ sangat-sangat tidak setuju sampai 7 = sangat-sangat setuju).

\section{c. Komitmen Organisasi}

Variabel Komitmen organisasi diukur dengan menggunakan instrumen versi pendek dari Mowday, Streers, dan Porter (1979) yang telah digunakan oleh Sholihin dan Pike (2010). Variabel komitmen organisasi diukur dengan menggunakan skala likert $(1=$ sangat tidak setuju, $7=$ sangat setuju) yang terdiri dari 9 item pertanyaan. Variabel komitmen organisasi diukur dengan menggunakan skala likert $(1=$ sangatsangat tidak setuju, $7=$ sangat-sangat setuju).

\section{HASIL}

Pengujian hipotesis dalam penelitian ini menggunakan structural equation modeling (SEM) dengan metode alternatif partial least square (PLS) menggunakan software WarpPLS 3.0. Pengujian hipotesis dalam penelitian ini dengan melihat nilai koefisien jalur dan nilai signifikansi ( $p$-value). Koefisien jalur digunakan untuk melihat arah hubungan dalam hipotesis. Nilai koefisien jalur positif berarti variabel independen berhubungan positif dengan variabel dependen, sedangkan untuk nilai koefisien jalur negatif diartikan variabel independen berhubungan negatif dengan variabel dependen.

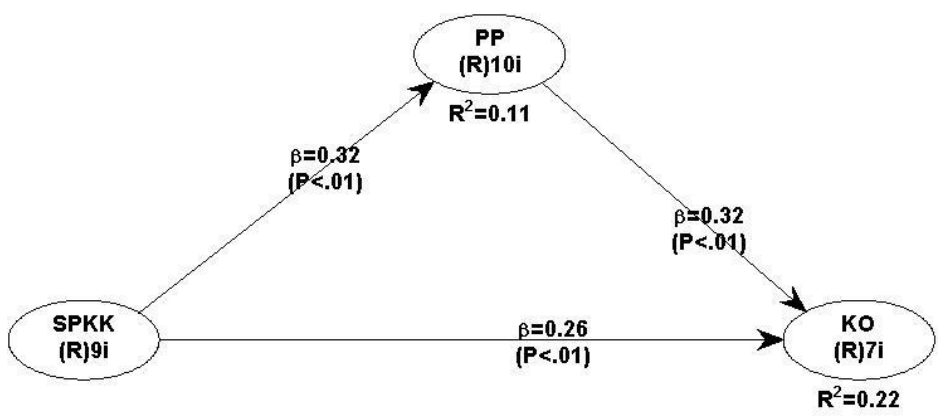

\section{Gambar 1 Hasil Evaluasi Model Penelitian}

Hipotesis yang diajukan dalam penelitian ini ada tiga. Hipotesis dalam penelitian ini dikatakan terdukung dengan $p$-value $<0,01$ (signifikan pada tingkat 1\%), $p$-value $<0,05$ (signifikan pada tingkat $5 \%$ ) serta $p$-value $<0,1$ (signifikan pada tingkat 10\%). Berikut nilai koefisien jalur, P-value dari hasil pengujian hipotesis menggunakan analisis SEM-PLS.

Tabel 1 Koefisien Jalur dan P-Value

\begin{tabular}{|l|l|c|}
\hline & Koefisien Jalur & P-Value \\
\hline SPKK PP & 0.32 & $<0,001^{* * *}$ \\
\hline SPKK KO & 0.26 & $<0,001^{* * *}$ \\
\hline PP KO & 0.32 & $<0,001^{* * *}$ \\
\hline
\end{tabular}

* Signifikan pada level 0,05 (2-tailed)

$*$ Signifikan pada level 0,01 (2-tailed)

$* * *$ Signifikan pad level 0,001 (2-tailed) 
Berikut ini penjelasan lebih jelas untuk masing-masing hipotesis yang diajukan dalam penelitian.

H1a: Sistem pengukuran kinerja komprehensif berpengaruh positif terhadap pemberdayaan psikologis

Hasil pengujian hipotesis yang ditunjukkan pada Tabel 1 menunjukkan bahwa sistem pengukuran kinerja komprehensif (SPKK) berpengaruh positif signifikan terhadap pemberdayaan psikologis (PP) yang dibuktikan dengan nilai koefisien jalur SPKK ? PP sebesar 0,32, P-value $<0,001$ (lebih kecil dari 0,001). Berdasarkan hasil tersebut maka dapat disimpulkan bahwa sistem pengukuran kinerja komprehensif berpengaruh positif terhadap pemberdayaan psikologis sehingga mendukung hipotesis 1a yang diajukan.

Hasil tesebut menunjukkan bahwa sistem pengukuran kinerja yang tersedia secara komprehensif dapat meningkatkan motivasi intrinsik individu yang sangat tinggi dalam pelaksanaan tugas manajerial. Penyelesaian tugas dari karyawan dapat terlaksana dengan baik ketika informasi yang tersedia tidak hanya berdasarkan informasi keuangan atau non-keuangan saja, akan tetapi informasi secara komprehensif. Motivasi karyawan akan meningkat ketika informasi yang dimiliki organisasi tersedia secara komprehensif. H1b: Sistem Pengukuran Kinerja komprehensif berpengaruh positif terhadap komitmen organisasi

Hasil pengujian hipotesis pada tabel menunjukkan bahwa sistem pengukuran kinerja komprehensif (SPKK) berpengaruh positif signifikan terhadap komitmen organisasi (KO) yang dibuktikan dengan nilai koefisien jalur SPKK? KO sebesar 0,26, P-value <0,001 (lebih kecil dari
0,001). Berdasarkan hasil tersebut maka dapat disimpulkan bahwa sistem pengukuran kinerja komprehensif berpengaruh positif terhadap komitmen organisasi sehingga mendukung hipotesis $1 b$ yang diajukan.

Hasil pengujian hipotesis $1 \mathrm{~b}$ di atas mengindikasikan bahwa informasi yang tersedia dari sistem pengukuran kinerja komprehensif yang informasinya lebih spesifik dapat meningkatkan keyakinan manajer unit untuk melaksanakan tugas sesuai dengan tujuan yang diharapkan oleh organisasi. Keyakinan individu tersebut membuat individu tersebut tetap bekerja dan bekerja dengan baik. Penelitian ini konsisten dengan penelitian Sholihin dan Pike (2010) yang menemukan bahwa sistem pengukuran kinerja komprehensif menjadikan komitmen organisasi meningkat.

H1c: Pemberdayaan psikologis berpengaruh positif terhadap komitmen organisasi

Hasil pengujian hipotesis yang ditunjukkan pada tabel tersebut menunjukkan bahwa pemberdayaan psikologis (PP) berpengaruh positif signifikan terhadap komitmen organisasi (KO) yang dibuktikan dengan nilai koefisien jalur PP? KO sebesar 0,32, P-value <0,001 (lebih kecil dari 0,001). Berdasarkan hasil tersebut maka dapat disimpulkan bahwa pemberdayaan psikologis berpengaruh positif terhadap komitmen organisasi sehingga mendukung hipotesis 1c yang diajukan.

Hasil pengujian hipotesis $1 \mathrm{c}$ di atas, menunjukkan bahwa karyawan yang yang diberdayakan akan meningkatkan komitmen organisasi. Konsistensi penelitian ini sesuai dengan penelitian yang dilakukan oleh Castro et al. (2008) yang menyatakan bahwa pemberdayaan psikologis meningkatkan komitmen organisasi. 


\section{E. KESIMPULAN}

Penelitian ini memiliki tujuan untuk menginvestigasi pengaruh dari sistem pengukuran kinerja komprehensif terhadap pemberdayaan psikologis dan komitmen organisasi. Selain itu, penelitian ini juga ingin menginvestigasi pengaruh pemberdayaan psikologis terhadap komitmen organisasi.

Hasil penelitian ini dapat disimpulkan bahwa sistem pengukuran kinerja komprehensif berpengaruh positif dan signifikan terhadap pemberdayaan psikologis. Dengan adanya sistem pengukuran kinerja secara komprehensif maka informasi menjadi lebih spesifik, relevan dan andal, sehingga informasi yang dibutuhkan oleh karyawan tersedia dan dapat dipergunakan dengan baik yang pada akhirnya akan berdampak pada meningkatkan motivasi dalam bekerja yakni pemberdayaan psikologisnya.

Kesimpulan berikutnya yaitu sistem pengukuran kinerja komprehensif yang informasinya lebih spesifik dapat meningkatkan keyakinan manajer unit untuk melaksanakan tugas sesuai dengan tujuan yang diharapkan oleh organisasi. Keyakinan individu tersebut membuat individu tersebut tetap bekerja dan bekerja dengan baik. Penelitian ini konsisten dengan penelitian Sholihin dan Pike (2010) yang menemukan bahwa sistem pengukuran kinerja komprehensif menjadikan komitmen organisasi meningkat.

Kesimpulan terakhir dalam penelitian ini yaitu pemberdayaan psikologis meningkatkan komitmen organisasi. Bukti ini konsisten dengan penelitian Castro et al. (2008). Ketika karyawan merasa diberdayakan, maka komitmen dalam sebuah organisasi tersebut akan meningkat, karena motivasi bekerjanya juga baik.

\section{F. DAFTAR RUJUKAN}

Allen, N.J. dan J.P. Meyer. 1990. The Measurement and Antecedents of Affective, Continuance and Normative Commitment to the Organization. Journal of Occupational Psychology. 63: 1-18.

Anthony, R.N. dan V. Govindarajan. 2007. Management Control System. New York: Mc Graw Hill International Edition.

Balfour, D.L., dan B. Wechsler. 1991. Commitment, Performance, and Productivity in Public Organization. Public Productivity and Management Riview. 14 (4): 355367.

Bandura, A. 1986. Social Foundations of Thought and Action: A Social Cognitive Theory. New Jersey: Prentice Hall.

Banker, R.D., H. Chang dan M.J. Pizzini. 2004. The Balanced Scorecard: Judgmental Effects of Performance Measures Linked to Strategy. The Accounting Riview. 79 (01): $1-23$.

Bhatnagar, J. 2005. The Power of Psychological Empowerment as an Antecedent to Organizational Commitment in Indian Managers. Human Resource Development International. 8 (4): 419-433.

Bliese, Paul D., Carl Andrew Castro. 2000. Role Clarity, Work Overload and Organizational Support: Multilevel Evidence of the Importance of Support. Work and Tress. 14: $65-73$.

Bogt, H.J.T. 2008. Management Accounting Change and New Public Management in Local Government: A Reassessment of Ambitions and Results An Institutionalist Approach to Accounting Change in the Dutch Public Sector. Financial Account- 
ability and Management. 24 (3): 210241.

Bowen, D.E. dan E.E. Lawler. 1992. The Empowerment of Service Worker: What, Why, How, and When. Sloan Management Riview. 33: 31-39.

Camilleri, E. dan B.I.J.M.V.D. Heijden. 2007. Organizational Commitment, Public Motivation, and Performance within the Public Sector. Public Performance and Management Review. 31(2): 241-274.

Carmichael, D.R. 1970. Behavioral Hypotheses of Internal Control. The Accounting Review. 45 (2): 235-245.

Castro, C.B., M.M.V. Perinan, dan J.C.C. Bueno. 2008. Transformational Leadership and Followers' Attitudes: the Mediating Role of Psychological Empowerment. The International Journal of Human Resource Management. 19 (10): 1842-1863. Cavalluzzo, K.S., dan C.D. Ittner. 2004. Implementing Performance Measurement Innovations: Evidence from Government. Accounting, Organizations and Society. 29: 243-267.

Chenhall, R.H. 2005. Integrative Strategic Performance Measurement Systems, Strategic Alignment of Manufacturing, Learning and Strategic Outcomes: An Exploratory Study. Accounting, Organizations and Society. 30: 395-422.

Chong, V.K., dan Ian R.C. Eggleton. 2007. The Impact of Reliance on Incentive- Based Compensation Schemes, Information Asymmetry and Organizational Commitment on Managerial Performance. Management Accounting Research. 18: 312342.
Collins, F. 1982. Managerial Accounting Systems and Organizational Control: A Role Perspective. Accounting, Organizations, and Society. 7: 107-112.

Conger, J.A. dan R.N. Kanungo. 1988. The Empowerment Process: Integrating Theory and Practice. The Academy of Management Review. 13 (3): 471-482.

Donnelly, J.H. dan J.H. Ivancevich. 1975. Role Clarity and the Salesman. Journal of Marketing: 71-74.

Garengo, P., S. Biazzo, dan U.S. Bititci. 2005. Performance Measurement Systems in SMEs: A Review for a Research Agenda. International Journal of Management Reviews. 7 (1): 25-47.

Gibson, J.L., Ivamcevich, J.T., dan Donnelly, J.H. 1996. Organisasi. Edisi 8. Jilid

1. Jakarta: Binarupta Aksara.

Gudono. 2014. Analisis Data Multivariat. Yogyakarta: BPFE.

Gregory, B.T, M.D. Albritton, dan T. Osmonbekov. 2010. The Mediating Role of Psychological Empowerment on the Relationships between P-O Fit, Job Satisfaction, and In-role Performance. Jurnal Business Psychology. 25: 639-647.

Hackman, J.R., dan G.R. Oldman. 1976. Motivation through the Design of Work: Test a Theory. Organizational Behavior and Human Performance. 16: 250-279.

Hair, J., T. Hult, C. Ringle, dan M. Sartstedt. 2013. A Primer on Partial Squares Structural Equation Modeling (SEM-PLS). Los Angeles: Sage.

Hair, J.W.C.B., B.J. Babin, dan R.E. Anderson. 2010. Multivariate Data Analysis: Global Perspective. Edisi Tujuh. New York: Pearson. 
Hair, Joseph. F, Thomas M. Hult, dan Christian M. Ringle. 2014. A Primer on Partial Least Squares Structural Equation Modeling (PLS-SEM). Los Angeles: Sage.

Halim, A. dan S. Kusufi. 2012. Akuntansi Sektor Publik: Teori, Konsep dan Aplikasi. Jakarta: Salemba Empat.

Hall, M. 2008. The Effect Comprehensive Performance Measurement Systems on Role Clarity, Psychological Empowerment and Managerial Performance. Accounting, Organizational and Society. 33: 141-163.

Hartono, Jogiyanto H.M., dan Willy Abdillah. 2009. Konsep dan Aplikasi PLS untuk Penelitian Empiris. Yogyakarta: BPFE.

Harvey, P., K. Madison, M. Martinko., dan T.R. Crook. 2014. Attribution Theory in the Organizational Sciences: the Road Traveled and the Path Ahead. The Academy of Management Perspectives. 28 (2): 128146.

Hassan, S. 2013. The Importance of Role Clarification in Workgroups: Effects on Perceived Role Clarity, Work Satisfaction, and Turnover Rates. Public Administration Review. 73: 716-725.

Hood, C. 1991. A Public Management for All Seasons. Public Administration. 6 (3): 319.

Hood, C. 1995. New Public Management in the 1980s: Variation and a Theme, Accounting. Organizations and Society. 20: 93109.

Ilgen, D.R.C.D. Fisher, and M.S. Taylor. 1979. Consequences of Individual Feedback on Behavior in Organizations. Journal of Applied Psychology. 64 (4): 349-371.

Ismail, A., H.A. Mohamed, A.Z. Sulaiman, M.H. Mohamad, dan M.H. Yusuf. 2011. An Empirical Study of the Relationship be- tween Transformational Leadership, Empowerment and Organizational Commitment. Business and Economics Research Journal. 2(1): 89-107.

Jansen, E.P. 2008. New Public Management: Perspectives on Performance and the Use of Performance Information. Financial Accountability and Management. 24 (2): 169-191.

Kaplan, R.S. and D.P. Norton. 1996. Linking the Balanced Scorecard to Strategy. California Management Review. 39 (1): 5379.

Kaplan, R.S. and D.P. Norton. 1996. Translating Strategy into Action: The Balanced Scorecard. Boston: Harvard Business School Press.

Kloot, L. dan J. Martin. 2000. Strategic Performance Management: A Balanced Approach to Performance Management Issues in Local Government. Management Accounting Research. 11: 231-251.

Kren, L. 1992. Budgetary Participation and Managerial Performance: the Impact of Information and Environmental Volatility. The Accounting Review. 67(3): 511-526.

Kunze, F., S.A. Boehm, dan H. Bruch. 2011. Age Diversity, Age Discrimination Climate and Performance Consequences. Journal of Organizational Behavior. 32: 264-290.

Lan, Z., dan H.G. Rainey. 1992. Goals, Rules and Effectiveness in Public, Private and Hybrid Organizations: More Evidence on More Evidence on Frequent Assertions about Differences. Journal of Public Administration Research and Theory. J-PART. 2 (1): 5-28.

Lau, C.M. 2011. Nonfinancial and Financial Performance Measures: How Do They 
Affect Employee Role Clarity and Performance?. Advances in Accounting, incorporating Advances in International Accounting. 27: 286-293.

Lau, C.M., dan A. Moser. 2008. Behavioral Effects of Nonfinancial Performance Measures: The Role of Procedural Fairness. Behavioral Research in Accounting. 20 (2): 55-71.

Lipe, M., dan S.E. Salterio. 2000. The Balanced Scorecard: Judgmental Effects of Common and Unique Performance Measures. The Accounting Review. 75: 283-298.

Luckett, P.F., dan I.R.C. Eggleton. 1991. Feedback and Management Accounting: a Review of Research into Behavioural Consequences. Accounting, Organizations and Society. 16: 371-394.

Luft, J.L. 2004. Discussion of Managers Commitment to the Goals Contained in a Strategic Performance Measurement System. Contemporary Accounting Research. 21 (4): 959-64.

Maciariello, J.A., dan C.J. Kirby. 1994. Management Control Systems: Using Adaptive Systems to attain Control. NJ: Prentice Hall.

Mahama, Habib dan Mandy M. Cheng. 2012. The Effect of Managers' Enabling Perceptions on Costing System Use, Psychological Empowerment, and Task Performance. Behavioral Research in Accounting. 25: 89-114.

Mahoney, Thomas A., Thomas H. Jerdee dan Stephen J. Carroll. 1965. The Job(s) of Mangement. Industrial Relations, 97-110.

Malina, M.A., dan F.H. Selto. 2001. Communicating and Controlling Strategy: An Empirical Study of the Effectiveness of the Balanced Scorecard. JAMAR. 13: 47-90.
Mardiasmo. 2009. Akuntansi Sektor Publik. Yogyakarta: Andi.

Marginson, D., M. Laurie., R. Melvin., dan Z.T. Van. 2014. Examining a Positive Psychological Role for Performance Measures. Management Accounting Research. 25: 6375.

Mels, C.B.G. 1995. A Causal Model to Evaluate the Relationships among Supervision, Role stress, Organizational Commitment and Internal Service Quality. European Journal of Marketing. 29 (2): 23-42.

Mowday, R.T, R.M. Streers, dan L.W. Porter. 1979. The Measurement of Organizational Commitment. Journal of Vocational Behavior. 14: 224-247.

Mukherjee, A. dan N. Malhotra. 2006. Does Role Clarity Explain Employee- Perceived Service Quality: A Study of Antecedents and Consequences in Call Centres. International Journal of Service Industry Management. 17: 444-473.

Neely, A., M. Gregory, dan K. Platts. 1995. Performance Measurement System Design. International Journal of Operations and Production Management. 25 (12): 12281263.

Newman, A., dan A.Z. Sheikh. 2012. Organizational Commitment in Chinese Small and Medium Sized Enterprises: the Role of Extrinsic, Intrinsic and Social Rewards. The International Journal of Human Resource Management. 23 (2): 349-367.

Nielsen, P.A. 2014. Learning from Performance Feedback: Performance Information, Aspiration Levels and Managerial Priorities. Public Administration. 92(1): 142-160.

Nordiawan, D. dan A. Hertianti. 2010. Akuntansi Sektor Publik. Jakarta: Salemba Empat. 
Otley, D.T. 1980. The Contingency Theory of Management Accounting: Achievement and Prognosis. Accounting, Organizations and Society. 5: 413-428.

Pollanen, R.M. 2014. Performance Measurement and Control Systems Evidence from Canadian Organization. International Journal of Business, Accounting, and Finance. 8 (1): 79-97.

Posner, B.Z. dan D.A. Butterfield. 1978. Role Clarity and Organizational Level. Journal of Management. 4: 81-90.

Rahman, Syaiful., Nasir, Muhammad., \& Handayani Rr. Sri. 2007. Pengaruh Sistem Pengukuran Kinerja Terhadap Kejelasan Peran, Pemberdayaan Psikologis dan Kinerja Manajerial. Simposium Nasional Akuntansi $X$.

Randolph, W.A. 1995. Navigating the Journey to Empowerment. Organizational Dynamics: $18-32$.

Reichers, A.E. 1985. A Review and Reconceptualization of Organizational Commitment. The Academy of Management Review. 10 (3): 465-476.

Rose, Raduan Che, N. Kumar, dan O.G. Pak. 2009. The Effect of Organizational Learning on Organizational Commitment, Job Satisfaction and Work Performance. The Journal of Applied Business Research. 25 (6): 55-66.

Sawyer, J.E. 1992. Goal and Process Clarity: Specification of Multiple Constructs of Role Ambiguity and a Structural Equation Model of Their Antecedents and Consequences. Journal of Applied Psychology. 77: 130-142.

Shields, M.D., F.J. Deng, dan Y. Kato. 2000. The Design and Effects of Control Systems: Tests of Direct and Indirect Effect
Models. Accounting. Organizations and Society. 25: 185-202.

Sholihin, M. dan D. Ratmono. 2013. Analisis SEM-PLS dengan WarpPLS 3.0. Yogyakara: Penerbit Andi.

Sholihin, M. dan R. Pike. 2009. Fairness in Performance Evaluation and its Behavioral Consequences. Accounting and Business Research. 04: 397-413.

Sholihin, M. dan R. Pike. 2010. Organizational Commitment the Police Service: Exploring the Effect of Performance Measurement, Prosedural Justice and Interpersonal Trust. Financial Accountability and Management. 24 (6): 392-421.

Siagian, S.P. 2004. Teori Motivasi dan Aplikasinya. Jakarta: Rineka Cipta. Simons, R. 2000. Performance Measurement and Control Systems to Implementing Strategy: Text and Cases. Upper Sadle River: Pretice Hall.

Spekle, R.F., dan F.H.M. Verbeeten. 2014. The Use of Performance Measurement Systems in the Public Sector: Effects on Performance. Management Accounting Research. 25: 131-146.

Spreitzer, G.M. 1995. Psychological Empowerment in the Workplace: Dimensions, Measurement and Validation. Academy of Management. 18 (5): 1442-1465.

Spreitzer, G.M. 1996. Social Structural Characteristics of Psychological Empowerment. Academy of Management. 39 (2): 483504.

Steers, R.M. 1976. Factors Affecting Job Attitude in a Goal Setting Environment.

The Academy of Management Journal. 19 (1): 6-16.

Stevens, J.M., J.M. Beyer dan H.M. Trice. 1978. Assessing Personal, Role, and Orga- 
nizational Predictors of Managerial Commitment. The Academy of Management Journal. 21(3): 380-396.

Stoner, J.A.F, Edward F., dan Daniel R.G.Jr. 1995. Management. Six Edition. New Jersey: Prentice Hall.

Supriyadi. 2010. The Moderating Effect of Prosedural Justice on the Effectiveness of the Balance Scorecard in Improving Managerial Performance through Organizational Commitment. Gadjah Mada International Journal of Business. 12 (3): 415-434.

Tan, S.L.C., dan C.M. Lau. 2012. The Impact of Performance Measures on Employee Fairness Perceptions, Job Satisfaction and Organizational Commitment. JAMAR. 10: 57-72.

Teas R.K., J.G. Wacker, dan R.E. Hughes. 1979. A Path Analysis of Causes and Consequences of Salespeople's Perceptions of Role Clarity. Journal of Marketing Research. 16 (3): 355-369.

Thomas, K.W. dan B.A. Velthouse. 1990. Cognitive Elements of Empowerment: An Interpretive Model of Intrinsic Task Motivation. The Academy of Management Review. 15 (4): 666-681.
Ugboro, Isaiah O., dan K. Obeng. 2000. Top Management Leadership, Employee Empowerment, Job Satisfaction in TQM Organizations: an Empirical Study. Journal of Quality Management. 5: 247-272.

Wang, X. 2002. Assessing Performance Measurement Impact: a Study of U.S Local Government. Public Performance and Management Review, 26: 26-43.

Webb, R.A. 2004. Managers' Commitment to the Goals Contained in a Strategic Performance Measurement System. Contemporary Accounting Research. 21: 925-958.

Weiner, B. 2010. The Development of an Attribution-Based Theory of Motivation: A History of Ideas. Educational Psychologist. 45(1): 28-36.

Woods, M. 2009. A contingency Theory Perspective on the Risk Management Control System within Birmingham City Council. Management Accounting Research. 20: 69-81.

Yousef, D.A. 2002. Job Satisfaction as a Mediator of the Relationship between Role Stressors and Organizational Commitment. Journal of Managerial Psychology. 17 (4): 250-266. 
Accounting and Management Journal, Vol. 1, No. 2, December 2017 